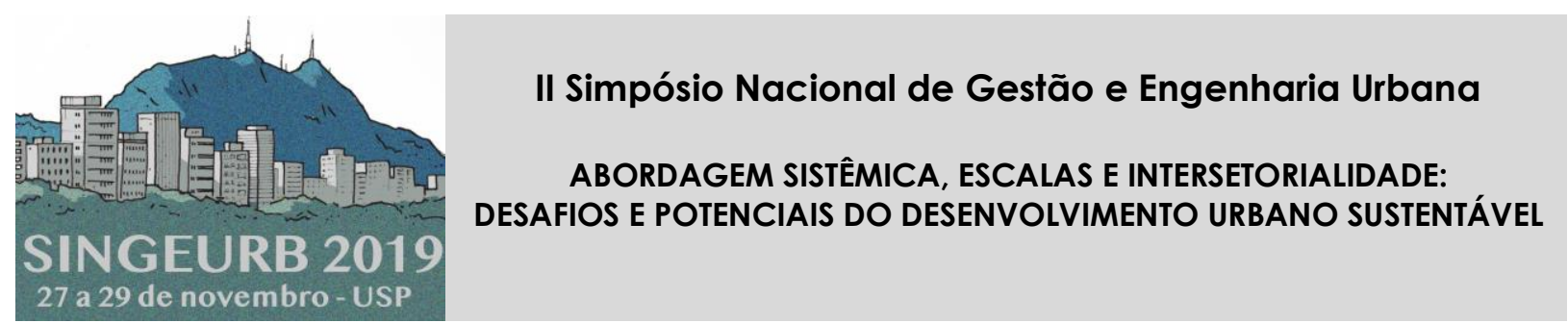

\title{
A boa governança na esfera pública'
}

\section{Good governance in the public sphere}

\author{
Benini, Sandra Medina'; Rosin, Jeane Aparecida Rombi de Godoy ${ }^{2}$ \\ 1 UNIVAG - Centro Universitário, Av. Dom Orlando Chaves, 2655 - Cristo Rei, \\ Várzea Grande - MT, Brasil e e-mail: arquiteta.benini@gmail.com \\ 2 UNIVAG - Centro Universitário, e-mail: urbanista.jeane@gmail.com
}

\begin{abstract}
RESUMO
Este artigo teve por objetivo analisar a governança pública na Estância Turística de Tupã/SP. Considera-se que governança é a capacidade do Estado em implementar políticas públicas, em especial, no atendimento das demandas sociais de modo articulado à decisão do Governo, por intermédio de mecanismos e procedimentos participativos. Para o desenvolvimento deste ensaio, adotou-se como parâmetro de referência ao processo de governança, a investigação da utilização de instrumentos de políticas públicas como a Agenda 21 e o Plano de Diretor, considerando a interlocução dos gestores públicos com os atores sociais e a intervenção do Ministério Público. Como procedimento metodológico, optou-se por uma pesquisa qualitativa, onde a construção empírica foi delimitada pelas realidades concretas e históricas, que retratam o contexto social, técnico e político na administração pública (período de 2001 a 2016). A partir de tais procedimentos, a pesquisa constatou que o processo de Agenda 21 adotado nas gestões públicas ocorridas no período entre 2005/2008 e 2009/2012, não apenas subsidiou, como também legitimou a implementação do Plano Diretor e seus desdobramentos em diversas ações, assegurando assim, efetividade do processo de governança.
\end{abstract}

Palavras-chave: Gestão Pública, Governanças, Eficiência.

\begin{abstract}
This article aimed to analyze public governance in the Tupã / SP Tourist Resort. Governance is considered to be the ability of the State to implement public policies, especially in meeting social demands in an articulated way to the Government's decision, through participatory mechanisms and procedures. For the development of this essay, it was adopted as a benchmark for the governance process, the investigation of the use of public policy instruments such as Agenda 21 and the Director Plan, considering the interlocution of public managers with social actors and intervention of the Public Ministry. As a methodological procedure, a qualitative research was chosen, where the empirical construction was delimited by the concrete and historical realities, which portray the social, technical and political context in the public administration (period from 2001 to 2016). Based on these procedures, the research found that the Agenda 21 process adopted in public administrations during the period between 2005/2008 and 2009/2012 not only subsidized but also legitimized the
\end{abstract}

\footnotetext{
${ }^{1}$ BENINI, Sandra Medina; ROSIN, Jeane Aparecida Rombi de Godoy. A boa governança na esfera pública In: II SIMPÓSIO NACIONAL DE GESTÃO E ENGENHARIA URBANA: SINGEURB, 2019, São Paulo. Anais... Porto Alegre: ANTAC, 2019.
} 
implementation of the Master Plan and its developments in several actions, thus ensuring the effectiveness of the governance process.

Keywords: Public Administration, Governance, Efficiency.

\section{INTRODUÇÃO}

Frente aos desacertos e às intencionalidades que vêm corroendo a credibilidade dos gestores públicos e culminando na intensificação do quadro de miséria em que se encontram muitos brasileiros, tratar de um tema como a governança é acender a esperança da probidade pública. Por esta razão, neste artigo propõe-se uma reflexão sobre importância da boa governança na esfera pública, conforme prevê o Princípio da Eficiência², uma condição sine qua non para restabelecer a credibilidade das atividades laborais exercidas pelos gestores públicos.

Para o desenvolvimento deste artigo, a governança foi abordada pela capacidade do Estado em implementar políticas públicas dedicadas ao atendimento das demandas sociais de modo articulado à decisão do Governo, por intermédio de mecanismos e procedimentos participativos.

Considerando o universo da pesquisa desenvolvida, optou-se por apresentar um estudo de caso realizado na Estância Turística de Tupã/SP, onde foi possível identificar uma experiência que se revelou diferenciada por buscar novos procedimentos metodológicos para implantação do processo de governança.

O estudo foi balizado por um recorte temporal delimitado entre o ano de 2001 e $01^{\circ}$ trimestre do ano de 2016, o que permitiu realizar uma análise comparativa de quatro gestões públicas, de modo a identificar fatos e ações adotados na administração pública que revelassem aspectos específicos ao enquadramento conceitual necessário para compreensão de um processo de governança.

\section{GOVERNANÇA PÚBLICA}

Difundido pelo World Bank (1992) e acolhido pelas demais instituições Internacionais, o termo governance ou governança é definido como o "[...] poder [que] é exercido na administração dos recursos econômicos e sociais do país, com vistas ao desenvolvimento". Em outras palavras, a governança está relacionada à capacidade dos governos em planejar, estabelecer metas, formular e implementar políticas para construção de um "Estado Eficiente", em que estejam conjugados processos decisórios, permitindo a articulação público-privada e demais segmentos sociais, na elaboração de políticas públicas (DINIZ, 1995, p. 400).

Segundo Alvim et al. (2006, p. 7-8), a eficiência do Estado depende

[...] do envolvimento e participação coordenados por atores sociais diversos, indica a necessidade de construção de arranjos institucionais que desempenhem as funções de mediações entre diversos interesses e necessidades, que agenciem os recursos materiais e humanos disponíveis ou criem novos recursos, e que estabeleçam programas e linhas de ação efetivas, legitimadas e assumidas pelos atores sociais envolvidos.

Para complementar, Alvim et al. (2006, p. 8) ressaltam que, a propositura de arranjos participativos da esfera pública favorecem, inclusive, avaliações posteriores das políticas públicas decorrentes do processo de governança, o que indica um "avanço democrático" nas esferas governamentais.

\footnotetext{
2 "O princípio da eficiência tem partes com as normas de 'boa administração', indicando que a Administração Pública, em todos os seus setores, deve concretizar atividade administrativa predisposta à extração do maior número possível de efeitos positivos ao administrado. Deve sopesar relação de custo-benefício, buscar a otimização de recursos, em suma, tem por obrigação dotar da maior eficácia possível todas as ações do Estado" (BASTOS, 1998, p. 235).
} 
A governança é caracterizada pelo poder social que "[...] media as relações entre Estado e Sociedade Civil" (JACOBI et al., 2012, p. 335), permitindo a "[...] construção de alianças e cooperação, mas também permeado por conflitos que decorrem do impacto das assimetrias sociais", bem como "seus reflexos no meio ambiente e das formas, de resistência, organização e participação dos diversos atores envolvidos" (JACOBI et al., 2012, p. 335). Nesse sentido, Rosenau (2000, p. 15-16) explica que o conceito de governança refere-se a "[...] atividades apoiadas em objetivos comuns, que podem ou não derivar de responsabilidades legais e formalmente prescritas e não depende, necessariamente, do poder de polícia para que sejam aceitas e vençam resistências", ou seja, a governança é um "fenômeno mais amplo que o governo; abrange as instituições governamentais, mas implica também mecanismos informais, de caráter não-governamental", permitindo que pessoas e organizações com interesses comuns possam dialogar e se articular para o atendimento de suas demandas. Deste modo, deve-se considerar que a governança detém a condição de "aumentar a capacidade de processar as demandas da sociedade e de articulá-las com os processos públicos e privados de tomadas de decisão" (MOURA; BEZERRA, 2014, p. 42).

Ao considerar sua abrangência, a governança é concebida a partir de um "[...] conjunto de princípios implícitos ou explícitos, normas, regras e procedimentos decisórios para os quais convergem as expectativas dos autores" (HAAS, 1980, p. 553). Para Silva (2004, p. 66), pode ser definida pela "capacidade da ação Estatal na implementação das políticas públicas, por intermédio de um conjunto de mecanismos e procedimentos participativos".

Em âmbito municipal, a governança ou governança local deve se aproximar da

[...] perspectiva normativa de 'bom governo', no sentido de postular a geração de best practices, através da inovação, participação, eficácia, sustentabilidade e confiança, como condições de se evitarem práticas predatórias nos governos: clientelismo, familismo amoral, corrupção, etc. (IVO, 2008, p. 320).

Deve-se ressaltar que, no âmbito da governança local e municipal, o desafio consiste em conhecer e ponderar sobre os múltiplos problemas e aspectos socioambientais presentes em um determinado território.

Para compreender como a boa governança pode ser instrumentalizada, se faz necessário realizar uma breve discussão sobre o papel da administração pública nesse processo. Neste sentido, Silva (2004, p. 67-68) destaca a função indutora do poder municipal no processo de participação social, entre outros aspectos.

O poder municipal tem o papel indutor do processo de participação social, mas as mudanças não se operam apenas na esfera governamental e administrativa. É preciso levar em consideração que existe uma mudança social que redefine o papel do cidadão, que deixa de ser apenas um eleitor para ser um interlocutor ativo no processo de gestão das políticas públicas.

Segundo o autor, essa visão traz implícita a "mudança paradigmática do processo participativo de intervenção social", a qual passa a adotar uma nova estrutura em que ocorre a "passagem de uma relação Estado-sociedade baseada numa estrutura vertical de autoridade, para uma estrutura de redes interativas horizontais" (SILVA, 2004, p. 72), em que o gestor público assume o papel de articulador das diversas demandas sociais.

Nota-se então, que a boa governança está associada a um modelo alternativo de gestão pública onde, o direito de participação permite a população exercer um papel fundamental na tomada de decisão, ao contribuir para o alcance de sua finalidade primordial - a qualidade no serviço público (Figura 1). 
Figura 1 - Boa governança na Administração Pública

BOA GOVERNANÇA

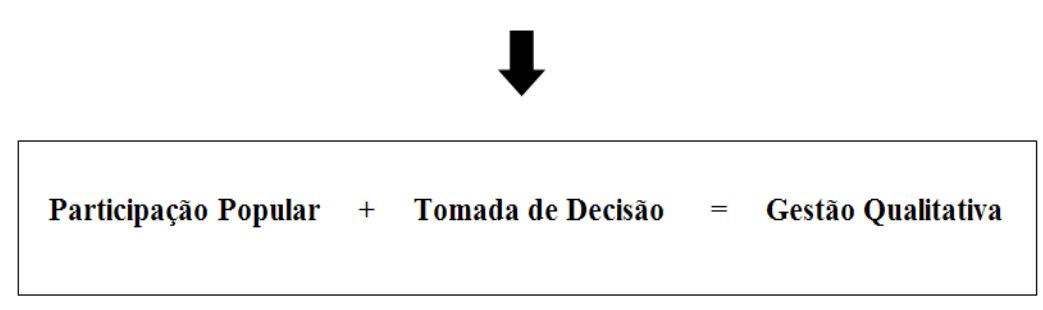

Fonte: Os autores

Neste novo arranjo institucional, a Administração Pública deve adotar estratégias que assegure o monitoramento e avaliação dos serviços prestados, de modo que todo cidadão possa ter acesso e acompanhar o desempenho dos órgãos gestores.

\section{PROCEDIMENTOS METODOLÓGICOS}

O Estudo de Caso foi realizado com base na análise do processo de gestão em tela durante quatro gestões administrativas do Município, distintas e sequenciais. Para o desenvolvimento da pesquisa, se fez necessário empreender uma análise a respeito do processo de implementação da Agenda 21 da Estância Turística de Tupã/SP, com o objetivo de verificar sua contribuição - enquanto instrumento de governança, para melhoria da qualidade de vida do espaço urbano.

Como estratégia de pesquisa, utilizaram-se, entre outros instrumentos empíricos, tais como anteriormente apresentados, o estudo de caso, que segundo Yin (2001, p. 68), permite "seguir a uma lógica de replicação", e apresentar resultados similares ou contrários àqueles previstos no "princípio da investigação". Com base em tais pressupostos, a realização do estudo empírico possibilitou uma análise cautelosa ao considerar os componentes (sociais, ambientais, culturais e políticos) envolvidos no processo de implementação da Agenda 21 local.

Portanto, a aplicação desse método de análise, demonstrou dados e informações empíricas específicas ao modo em que se deu sua construção nos períodos analisados. Em síntese, o conjunto de informações elaborado com vistas a possibilitar a avaliação concernente à análise, foi composto por entrevistas com agentes sociais e políticos, representantes de ONGs, poder público, sociedade civil, complementados por uma investigação exaustiva de publicações relacionadas ao tema na imprensa local. A guisa desse processo metodológico, os resultados obtidos foram organizados e sistematizados em gráficos e tabelas e compatibilizados com os preceitos que orientaram a Agenda 21, sob o enfoque deste estudo - aqueles relacionados aos fundamentos da governança - de forma a possibilitar uma leitura abrangente, com o propósito de alcançar uma análise fidedigna.

\section{ESTUDO DE CASO}

Segundo O IBGE ${ }^{3}$ (2010) a população da Estância Turística de Tupã, encontra-se distribuída entre 60.930 pessoas residentes na área urbana e 2.546 na área rural. O grau de urbanização no município é de $95 \%$, enquanto que a média do Estado de São Paulo é de 95,94\%.

Estudo de Caso da Estância Turística de Tupã/SP teve objetivo identificar fatos ou ações da Administração Pública, dentro do recorte temporal compreendido entre 2001 até $01^{\circ}$ trimestre de 2016, que ofereçam indícios de um processo de governança.

Para o desenvolvimento desta pesquisa considerou-se como conceito de governança, a capacidade do Estado em implementar políticas públicas, em especial, no atendimento das

${ }^{3}$ IBGE - Instituto Brasileiro de Geografia e Estatística. 
demandas sociais de modo articulado à decisão do Governo, por intermédio de mecanismos e procedimentos participativos.

Como parâmetro de referência ao processo de governança, a pesquisa delimitou o estudo à investigação da utilização de instrumentos de políticas públicas, como a Agenda 21 e o Plano de Diretor, considerando a interlocução dos gestores públicos com os atores sociais e a intervenção do Ministério Público.

Como resultado, o protagonismo da agenda 21 enquanto instrumento norteador à revisão do Plano Diretor do município de Tupã, teve um papel estruturador para o desenvolvimento urbano ambiental, a partir de procedimentos metodológicos que pudessem legitimar o pacto social, oriundo dos princípios da gestão democrática - uma condição essencial para a efetividade da governança.

A presente pesquisa procurou compreender como os procedimentos administrativos e institucionais implementados no período compreendido entre 2005 a 2016, na Estância Turística de Tupã, Estado de São Paulo, possibilitaram alcançar uma gestão qualitativa, a qual poderia ser resultante da aplicação da Agenda 21 Local, enquanto mecanismo estratégico a implementação de uma política urbana baseada nos princípios da governança.

\section{CONCLUSÕES}

O conteúdo apresentado neste artigo teve como preocupação evidenciar que a maior atribuição concernente ao conceito de governança, bem como, ressaltar o protagonismo da agenda 21 enquanto instrumento norteador à revisão do Plano Diretor do município de Tupã-SP, por considerar seu papel estruturador para o desenvolvimento urbano ambiental, a partir de procedimentos metodológicos que pudessem legitimar o pacto social, oriundo dos princípios da gestão democrática - uma condição essencial para a efetividade da governança.

Como resultado a pesquisa constatou que o processo de Agenda 21 adotado nas gestões públicas que compreenderam o período entre 2005/2008 e 2009/2012, não apenas subsidiou, como também legitimou a implementação do Plano Diretor e seus desdobramentos em diversas ações, assegurando assim, efetividade da governança. Por fim, considerando o universo da pesquisa apresentada, que Agenda 21 da Estância Turística de Tupã pode ser considerada como um instrumento da boa governança.

\section{REFERÊNCIAS}

ALVIM, A. T. B. et al. Desafios das políticas urbanas no Brasil: a importância dos instrumentos de avaliação e controle social. Cadernos de Pós-Graduação em Arquitetura e Urbanismo, v. 6, n. 1, p. 1-24, 2016.

BASTOS, C. R. Curso de direito constitucional. São Paulo: Saraiva, 1998.

HAAS, E. B. Technological self-reliance for Latin America: the OAS contribution. International Organization, v. 34, n. 4, p. 541-570, 1980.

IVO, A. B. L. Sociologia, modernidade e questão social. Tese (doutorado). Universidade Federal de Pernambuco. CFCH. Sociologia. Recife: O Autor, 2008.

JACOBI, P. R.; GUNTHER, W. M. R.; GIATTI, L. L. Agenda 21 e Governança. Estudos Avançados, São Paulo, v. 26, n. 74, p. 331-340, 2012.

MOURA, A. S. de; BEZERRA, M. do C. de L. O papel da governança na promoção da sustentabilidade das políticas públicas no Brasil. RMP - Revista dos Mestrados Profissionais, v. 3, n. 2, jul.-dez. 2014. 
ROSENAU, J. N. Governança, ordem e transformação na política mundial. In: CZEMPIEL, E.-O. Governança sem governo: ordem e transformação na política mundial. Brasília: UnB; São Paulo: Imprensa Oficial do Estado, 2000. p. 11-46.

SILVA, G. T. da. Gestão pública e transformação social no Brasil. In: FUNDAÇÃO KONRAD ADENAUER - FKA. Participação cidadã: novos conceitos e metodologias. Fortaleza: Expressão Gráfica e Editora, 2004. p. 61-86.

YIN, Robert K. Estudo de caso: planejamento e método. Trad. GRASSI, Daniel, 2. Ed. Porto Alegre: Bookman, 2001. 